\title{
MLLT10 and IL3 rearrangement together with a complex four-way translocation and trisomy 4 in a patient with early T-cell precursor acute lymphoblastic leukemia: A case report
}

\author{
MONEEB A.K. OTHMAN ${ }^{1}$, JOANA B. MELO ${ }^{2,3}$, ISABEL M. CARREIRA ${ }^{2,3}$, MARTINA RINCIC ${ }^{1,4}$, \\ EYAD ALHOURANI $^{1}$, KATHLEEN WILHELM ${ }^{1,5}$, BERND GRUHN $^{5}$, ANITA GLASER ${ }^{1}$ and THOMAS LIEHR ${ }^{1}$ \\ ${ }^{1}$ Jena University Hospital, Friedrich Schiller University, Institute of Human Genetics, Jena, Germany; \\ ${ }^{2}$ Laboratory of Cytogenetics and Genomics, Faculty of Medicine, University of Coimbra, Coimbra; \\ ${ }^{3}$ CIMAGO, Centro de Investigação em Meio Ambiente, Genéticae Oncobiologia, Coimbra, Portugal; \\ ${ }^{4}$ Croatian Institute of Brain Research, Zagreb, Croatia; ${ }^{5}$ Department of Pediatrics (Oncology and \\ Hematology), Jena University Hospital, Friedrich Schiller University, Jena, Germany
}

Received September 3, 2014; Accepted October 13, 2014

DOI: $10.3892 /$ or.2014.3624

\begin{abstract}
Cytogenetic classification of acute lymphoblastic leukemia (ALL) is primarily based on numerical and structural chromosomal abnormalities. In T-cell ALL (T-ALL), chromosomal rearrangements are identified in up to $70 \%$ of the patients while the remaining patients show a normal karyotype. In the present study, a 16-year-old male was diagnosed with T-precursor cell ALL and a normal karyotype after standard GTG-banding, was studied retrospectively ( $>10$ years after diagnosis) in frame of a research project by molecular approaches. In addition to molecular cytogenetics, multiplex ligation-dependent probe amplification (MLPA) and high resolution array-comparative genomic hybridization $(\mathrm{aCGH})$ were also applied. Thus, the following yet unrecognized balanced chromosomal aberrations were detected: $\operatorname{der}(3) \mathrm{t}(3 ; 5)(\mathrm{p} 23 ; \mathrm{q} 31.1), \operatorname{der}(5) \mathrm{t}(3 ; 5)(\mathrm{p} 23 ; \mathrm{q} 35.3)$, $\operatorname{der}(5) \mathrm{t}(5 ; 10)(\mathrm{q} 31.1 ; \mathrm{p} 12.3)$ and $\operatorname{der}(10) \mathrm{t}(5 ; 10)(\mathrm{q} 35.3 ; \mathrm{p} 12.3)$. The oncogene MLLT10 was involved in this rearrangement as was the IL3 gene; in addition, trisomy 4 was present. All of these clonal aberrations were found in $40 \%$ of the cells. Even if this complex karyotype would have been identified at the time of diagnosis, most likely no other protocol of anticancer therapy (ALL-BFM 95) would have been applied. Three months after the end of a successful 2-year treatment, the patient suffered from isolated bone marrow relapse and died of sepsis during ALL-REZ-BFM protocol treatment.
\end{abstract}

Correspondence to: Dr Thomas Liehr, Institut für Humangenetik, Postfach, D-07740 Jena, Germany

E-mail: thomas.liehr@med.uni-jena.de

Key words: early T-cell precursor acute lymphoblastic leukemia, molecular cytogenetics, MLLT10, IL3, array-CGH

\section{Introduction}

T-cell acute lymphoblastic leukemia (T-ALL) is an aggressive leukemia derived from malignant transformation of $\mathrm{T}$ cell progenitors and is more common in males than in females. T-ALL affects mainly older children and adolescents and represents $10-15 \%$ of pediatric and $25 \%$ of young adult ALL cases (1). Hyperdiploidy (>46 chromosomes) is found in $30 \%$ of childhood and $10 \%$ of adulthood ALL cases. Notably, high hyperdiploidy (51-65 chromosomes) has been connected with high survival rates and excellent outcome $(2,3)$, while low hyperdiploidy (47-50 chromosomes) has been associated with worse prognosis (4). The most commonly gained chromosomes in ALL are \#4, \#6, \#10,\#14, \#17, \#18, \#21 and X (5). Trisomy 4 is rarely observed as a sole cytogenetic abnormality in T-ALL (6). However, the mechanism for chromosomal gains in ALL and their role in leukemogenesis are still ambiguous $(7,8)$. In hyperdiploid karyotypes, the $\mathrm{t}(9 ; 22)(\mathrm{q} 34 ; \mathrm{q} 11), 11 \mathrm{q} 23$ (MLL gene) rearrangements, $\mathrm{t}(12 ; 21)(\mathrm{p} 13 ; \mathrm{q} 22), \mathrm{t}(1 ; 19)(\mathrm{q} 23 ; \mathrm{p} 13)$ and $\mathrm{t}(8 ; 14)(\mathrm{q} 24 ; \mathrm{q} 32)$ are the most common structural cytogenetic abnormalities in ALL. However, in T-ALL, involvement of the $\mathrm{T}$ cell receptor $(T C R)$ gene in $14 \mathrm{q} 11$ in rearrangements such as $\mathrm{t}(1 ; 14)(\mathrm{p} 31 ; \mathrm{q} 11), \mathrm{t}(10 ; 14)(\mathrm{q} 24 ; \mathrm{q} 11)$ or $\mathrm{t}(8 ; 14)(\mathrm{q} 24 ; \mathrm{q} 11)$ are frequently observed; also $\operatorname{del}(6)(\mathrm{q} 15)$ and $\operatorname{del}(1)(\mathrm{p} 32)$ have been described (3,9-11).

Still, cryptic structural chromosomal abnormalities were and are a challenge in the cytogenetics of T-ALL. For example, as the cryptic $\mathrm{t}(5 ; 14)(\mathrm{q} 35 ; \mathrm{q} 32)$ is known to be present in $20 \%$ of childhood and in $13 \%$ of adult T-ALL cases, this aberration is currently routinely tested by molecular (cyto)genetics, addressing the breakpoint on the TLX3 (HOX11L2) gene in $5 \mathrm{q} 35$ and to the promoter of the BCL11B gene in $14 \mathrm{q} 32$ (12). In addition, recent reports on newly detected cryptic chromosomal rearrangements such as the MLLT10 gene (previously $A F 10$, in 10p13), and MLL (in11q23) or PICALM (in 11q14) highlight the necessity to further study clinical cases as detailed as possible $(13,14)$. The goal of these studies must be, on the one hand, to provide the most accurate diagnosis to each 

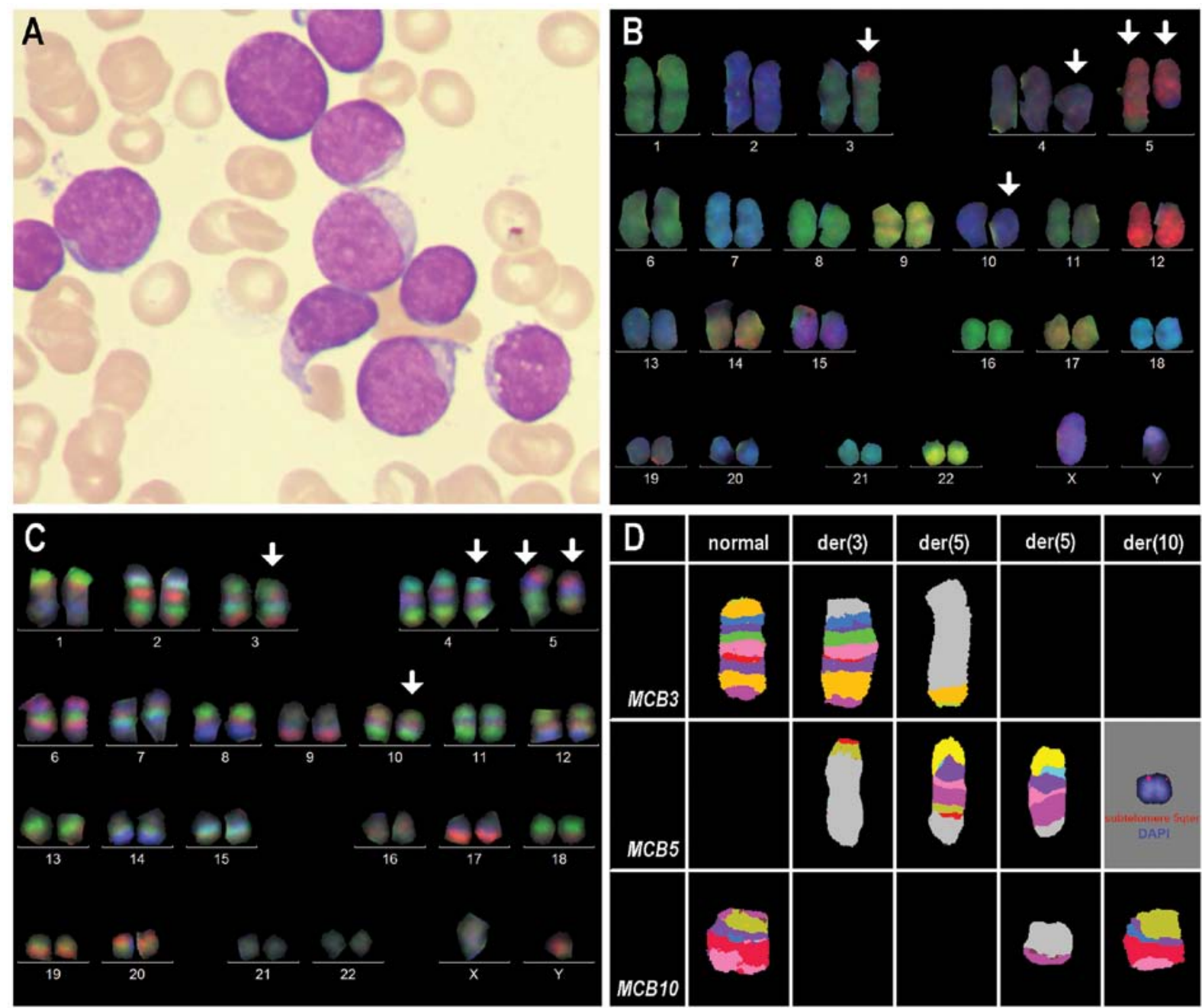

Figure 1. (A) Early T-cell precursor ALL cells of the presented patient depicted after Pappenheim staining. (B) Application of M-FISH revealed derivative chromosomes 3,5,5 and 10 (arrows). (C) mMCB results are shown as an overlay of three of the six used color channels. Evaluation was carried out as previously reported (21) using all 6 color channels and pseudocoloring. Breakpoints were determined as 3p23,5q31.1, 5q35.3X and 10p12.3. (D) aMCB probesets for chromosomes 3,5 and 10 confirmed the observed breakpoints after mMCB application. The breakpoint in $5 \mathrm{q} 35.5$ was confirmed by a subtelomeric probe $5 \mathrm{qter}$.

individual patient and, on the other hand, to achieve insights into the biology and pathogenesis of T-ALL.

In the present study, an adolescent T-precursor cell ALL case with an MLLT1O and IL3 gene rearrangement together with trisomy 4 in complex four-way translocation is characterized in detail retrospectively using molecular cytogenetics and molecular genetics. This leukemia subtype would currently be classified as early T-cell precursor ALL (15-17).

\section{Case report}

Clinical description. A 16-year-old male presented in 1998 for diagnostics due to fever and unclear symptoms of malaise. Immunophenotypic analysis of bone marrow cells revealed the following results: $\mathrm{HLA}_{-} \mathrm{DR}^{+}, \mathrm{TdT}^{+}, \mathrm{cyCD}^{+}, \mathrm{CD} 5$ weak, $\mathrm{CD}^{+}$, $\mathrm{CD}^{+}, \mathrm{CD}_{10}{ }^{+}, \mathrm{CD} 3^{+}, \mathrm{CD}_{3}{ }^{+}$and $\mathrm{CD} 34^{+}$. This supported a diagnosis of early T-ALL; at present, it would be classified as early T-cell precursor ALL (Fig. 1A).

The patient was treated according to the ALL-BFM 95 protocol; the continuation therapy was completed 24 months after the initial diagnosis. Three months later an isolated bone marrow relapse with acute thrombocytopenia was diagnosed, and treatment according to the ALL-REZ-BFM protocol was initiated. One month later the patient died due to an Aspergillus sepsis and still with $100 \%$ blasts in the bone marrow.

Tests conducted at diagnosis. Banding cytogenetic analysis was performed on an unstimulated bone marrow aspirate according to standard procedures. A total of 20 metaphases were available for cytogenetic evaluation and analyzed on a banding level of 300 bands per haploid karyotype (22). GTG-banding revealed a normal male karyotype in our laboratory, and also a second cytogenetic analysis on 25 metaphases performed 4 months after the initial diagnosis in another laboratory confirmed this test result. Molecular diagnostic PCR tests for gene fusions $B C R / A B L, M L L / A F 4$ and TEL/AML1 were negative (data not shown).

\section{Test conducted in retrospect}

Molecular cytogenetics. Fluorescence in situ hybridization (FISH) was performed according to standard procedures and/ or according to the manufacturer's instructions. 
Table I. Results of the locus-specific probes used for breakpoint analyses in metaphase FISH are listed.

\begin{tabular}{|c|c|c|c|c|}
\hline Cytoband & Position [hg18] & Genes/locus & Probe & Results (signals on...) \\
\hline 3pter & chr3:131,486-331,767 & D3S4559 & 3pTEL (Vysis) & $\operatorname{der}(5) t(3 ; 5)$ \\
\hline $3 \mathrm{p} 24.1$ & $\operatorname{chr} 3: 30,275,517-30,447,565$ & n.d. & RP11-69K20 & $\operatorname{der}(5) t(3 ; 5)$ \\
\hline $3 p 24.1$ & $\operatorname{chr} 3: 30,541,893-\mathbf{3 0 , 7 0 5 , 0 7 0}$ & STT3B & RP11-7I16 & $\operatorname{der}(5) t(3 ; 5)$ \\
\hline $3 \mathrm{p} 22.3$ & $\operatorname{chr} 3: \mathbf{3 2}, \mathbf{4 5 3}, \mathbf{7 3 2}-32,650,841$ & $\begin{array}{l}\text { GPDIL } \\
\text { GADL1 } \\
\text { OSBPL10 } \\
\text { CMTM7 } \\
\text { CMTM8 }\end{array}$ & RP11-524O15 & $\operatorname{der}(5) \mathrm{t}(3 ; 5)$ \\
\hline $3 p 22.2$ & $\operatorname{chr} 3: 38,928,115-39,088,251$ & n.d. & RP11-159A17 & $\operatorname{der}(3) t(3 ; 5)$ \\
\hline $5 q 22.2$ & chr5:112,073,070-112,236,540 & n.d. & RP11-107C15 & $\operatorname{der}(5) \mathrm{t}(5 ; 10)$ \\
\hline $5 q 23.1$ & chr5:117,308,035-117,479,091 & n.d. & RP11-567A12 & $\operatorname{der}(5) \mathrm{t}(5 ; 10)$ \\
\hline $5 q 23.3$ & chr5:126,045,879-126,232,850 & n.d. & RP11-434D11 & $\operatorname{der}(5) \mathrm{t}(5 ; 10)$ \\
\hline $5 q 23.3 \sim q 31.1$ & chr5:130,306,745-130,460,728 & $5^{\prime}$ of IL3 & RP11-114H7 & $\operatorname{der}(5) \mathrm{t}(5 ; 10)$ \\
\hline $5 q 31.1$ & chr5:131,424,246-131,426,795 & IL3 & n.a. & n.a. \\
\hline $5 q 31.1$ & chr5:131,817,004-131,977,063 & $3^{\prime}$ of IL3 & RP11-729C24 & $\operatorname{der}(3) t(3 ; 5)$ \\
\hline $5 q 31.1$ & chr5:135,739,999-135,916,051 & n.d. & RP11-114H21 & $\operatorname{der}(3) t(3 ; 5)$ \\
\hline $5 q 31.2$ & chr5:137,829,080-137,832,903 & EGR1 & LSI EGR1 & $\operatorname{der}(3) t(3 ; 5)$ \\
\hline $5 q 32.1$ & chr5:149,473,595-149,515,615 & PDGFRB & $\begin{array}{l}\text { POSEIDON } \\
\text { PDGFRB } \\
\text { (Kreatech) }\end{array}$ & $\operatorname{der}(3) \mathrm{t}(3 ; 5)$ \\
\hline $5 q 35.1$ & chr5:170,996,421-171,159,856 & n.d. & RP11-20O22 & $\operatorname{der}(3) \mathrm{t}(3 ; 5)$ and $\operatorname{der}(5) \mathrm{t}(3 ; 5)$ \\
\hline $5 q 35.2$ & chr5:173,985,900-174,153,222 & n.d. & RP11-47J7 & $\operatorname{der}(3) \mathrm{t}(3 ; 5)$ and $\operatorname{der}(5) \mathrm{t}(3 ; 5)$ \\
\hline $5 q 35.2$ & chr5:175,502,694-175,558,904 & n.d. & RP11-844P9 & $\operatorname{der}(3) \mathrm{t}(3 ; 5)$ and $\operatorname{der}(5) \mathrm{t}(3 ; 5)$ \\
\hline $5 q 35.3$ & chr5:176,550,923-176,735,050 & n.d. & RP11-265K23 & $\operatorname{der}(3) \mathrm{t}(3 ; 5)$ and $\operatorname{der}(5) \mathrm{t}(3 ; 5)$ \\
\hline $5 q 35.3$ & chr5:178,243,600-178,455,573 & 5' HNRNPH1 & RP11-281O15 & $\operatorname{der}(3) \mathrm{t}(3 ; 5)$ and $\operatorname{der}(5) \mathrm{t}(3 ; 5)$ \\
\hline $5 q 35.3$ & chr5:178,973,785-178,983,328 & HNRNPH1 & n.a. & n.a. \\
\hline $5 q 35.3$ & chr5:179,360,362-179,524,360 & 3' HNRNPH1 & RP11-39H3 & $\operatorname{der}(5) \mathrm{t}(5 ; 10)$ and $\operatorname{der}(5) \mathrm{t}(3 ; 5)$ \\
\hline $5 q 35.3$ & chr5:180,142,710-180,335,838 & n.d. & RP11-516K1 & $\operatorname{der}(5) \mathrm{t}(5 ; 10)$ and $\operatorname{der}(5) \mathrm{t}(3 ; 5)$ \\
\hline 5 qter & chr5:180,510,748-180,711,420 & D5S2907 & 5pTEL (Vysis) & $\operatorname{der}(5) \mathrm{t}(5 ; 10)$ and $\operatorname{der}(5) \mathrm{t}(3 ; 5)$ \\
\hline 10pter & chr10:292,280-292,670 & Z96139 & 10pTEL (Vysis) & $\operatorname{der}(5) \mathrm{t}(3 ; 5)$ \\
\hline $10 \mathrm{p} 12.31$ & chr10:20,782,567-20,938,614 & n.d. & RP11-51E20 & $\operatorname{der}(5) t(3 ; 5)$ \\
\hline $10 \mathrm{p} 12.31$ & $\operatorname{chr} 10: 21,321,413-\mathbf{2 1 , 4 9 5 , 2 6 4}$ & 5' MLLT10 & RP11-165O3 & $\operatorname{der}(5) t(3 ; 5)$ \\
\hline $10 \mathrm{p} 12.31$ & chr10:21,863,580-22,072,560 & MLLT10 & n.a. & n.a. \\
\hline $10 \mathrm{p} 12.31$ & chr10:22,399,352-22,575,929 & 3' MLLT10 & RP11-108B14 & $\operatorname{der}(5) \mathrm{t}(5 ; 10)$ \\
\hline
\end{tabular}

n.d., not determined; n.a., not available.

The following homemade probes and probe sets were used: i) 24-color-FISH using all human whole chromosome painting (WCP) probes (19); ii) FISH-banding probe sets as follows: genome-wide multitude multicolor banding (mMCB) and chromosome-specific high resolution array-proven multicolor banding (aMCB) (20-22); iii) DNA from bacterial artificial chromosome (BAC) probes (Table I) obtained from Resources Center (Oakland, CA, USA) were labeled by PCR with SpectrumGreen, SpectrumOrange or TexasRed-dUTP and applied in two- or three-color FISH approaches.
Additionally, the following commercially available probes were used: LSI EGR1/D5S23, D5S721 (EGR1 in 5q31; D5S23, D5S721 in 5p15.2; Abbott Molecular/Vysis, Mannheim, Germany),POSEIDON PDGFRB ( $5 q 33$ Break probe; Kreatech Diagnostics, Amsterdam, The Netherlands), and subtelomeric probes for 3p, 5p, 5q and 10p (3p in D3S4559; 5p in C84c11/ T3, 5q in D5S2907; 10p in Z96139; Abbott Molecular/Vysis).

A total of 10-15 metaphase spreads were analyzed, using a fluorescence microscope (Axio Imager Z1 mot; Carl Zeiss AG) equipped with appropriate filter sets to discriminate between 
a maximum of five fluorochromes and the counterstain DAPI (diaminophenylindol). Image capturing and processing were carried out using an ISIS imaging system (MetaSystems, Altlussheim, Germany).

DNA isolation. Genomic DNA was extracted from cells fixed in acetic acid-methonal (1:3) using the Puregene DNA purification kit (Gentra Systems, Inc., Minneapolis, MN, USA). DNA concentration was determined by a NanoDrop spectrophotometer. The quality of DNA was checked using agarose gel electrophoresis. DNA samples extracted from fixed cells of 2 healthy males and 2 healthy females by the same method were used as reference samples.

Multiplex ligation-dependent probe amplification (MLPA). The P377-A1 hematologic malignancies probemix and SALSA reagents were used for the present study (MRC-Holland, Amsterdam, The Netherlands). Amplified probes and GeneScan 500 ROX standard were separated by capillary electrophoresis using a 4-capillary ABI PRISM 3130XL Genetic Analyzer (Applied Biosystems, Foster City, CA, USA). Sizing of peaks and quantification of peak areas and heights were performed using the GeneMarker v1.9 software (Applied Biosystems). A minimum of 4 healthy control samples were included in each run.

High resolution array-comparative genomic hybridization $(a C G H)$. aCGH was performed using the Agilent SurePrint G3 Human Genome Microarray 180K (Agilent Technologies, Santa Clara, CA, USA), an oligonucleotide microarray containing $\sim 180,000$ probes 60 -mer with a $17-\mathrm{kb}$ average probe spacing. Genomic DNA of the patient was co-hybridized with a male control DNA (Agilent Technologies). Labeling was performed using the Agilent Genomic DNA Enzymatic Labeling kit (Agilent Technologies) according to the manufacturer's instructions. After hybridization, the aCGH slide was scanned on an Agilent scanner, processed with the Feature Extraction software (v.10.7) and results were analyzed using Cytogenomics (v2.9.1.3) using ADM2 as aberration algorithm.

Results of the retrospective analyses. Genome-wide 24-color FISH using all human WCP probes and FISH-banding analysis using the $\mathrm{mMCB}$ probe set were applied as initial tests in this retrospective case. Thereby, a previously unrecognized numerical aberration, trisomy 4 , and balanced translocations were identified between one chromosome 3 and 10, each, and both chromosomes 5. Overall, an abnormal karyotype was characterized as $47, \mathrm{XY},+4, \operatorname{der}(3) \mathrm{t}(3 ; 5)(\mathrm{p} 23 ; \mathrm{q} 31.1), \operatorname{der}(5)$ $\mathrm{t}(3 ; 5)(\mathrm{p} 23 ; \mathrm{q} 35.3), \operatorname{der}(5) \mathrm{t}(5 ; 10)(\mathrm{q} 31.1 ; \mathrm{p} 12.3), \operatorname{der}(10) \mathrm{t}(5 ; 10)$ (q35.3;p12.3)[8]/46,XY[13] (Fig. 1B and C).

Chromosome-specific aMCB confirmed these results (Fig. 1D) and locus-specific probes narrowed down the breakpoints according to NCBI36/hg18 as follows (Table I). i) The breakpoint in 3 p23 was determined between the positions 30,705,070 and 32,453,732; 6 OMIM genes are located there: STT3B, GPDIL, GADL1, OSBPL10, CMTM7 and CMTM8. ii) The breakpoint 5q31.1 locates between positions $130,460,728$ and $131,817,004$ and those flank the gene IL3 (interleukin 3 precursor) in 131,424,246-131,426,795. iii) The second breakpoint on chromosome 5 in subband q35.3 was mapped to positions $178,455,573$ to $179,360,362$; here the HNRNPH1 (heterogeneous nuclear ribonucleoprotein $\mathrm{H1}$ ) gene is included in $178,973,785-178,983,328$. iv) Finally, the breakpoint in 10p12.3 was narrowed down to localize between positions 21,495,264 and 22,399,352, where the MLLT10 (myeloid/lymphoid or mixed-lineage leukemia) gene has been mapped to $21,863,580-22,072,560$.

No submicroscopic changes were detected by MLPA and aCGH; only the trisomy 4 was observed in aCGH (data not shown).

\section{Discussion}

Chromosomal translocations in ALL may be missed in banding karyotyping due to several reasons. They may be cryptic, as they are not resolvable due to a similar or identical GTG-banding pattern; an example is the $\mathrm{t}(12 ; 21)(\mathrm{p} 13 ; \mathrm{q} 22)$ in childhood ALL (23). In addition, known aberrations may be masked in a complex karyotype (24). Finally, it may simply be difficult to obtain evaluable metaphases where chromosomes are well-spread and not clumsy or appearing as fuzzy with indistinct margins (25). In the present case the latter was the major problem. In the reanalyses, all well-spread metaphases were normal and all aberrant metaphases were clumsy and not evaluable in standard GTG-banding. Thus, cytogenetic analyses in two different laboratories missed the aberrations present in this case. Otherwise gross structural and a numerical aberration would not have been overlooked like in this case which were detected in retrospect by molecular cytogenetics.

Trisomy 4 as a sole abnormality is rare in acute myeloid leukemia (AML) (26) but is scarce in ALL and is not associated with a clear prognosis $(6,27,28)$. In pediatric ALL, trisomy 4 has been reported to be associated with a favorable outcome suggesting that children who have trisomies of both chromosomes 4 and 10 may have a particularly low risk of treatment failure $(3,5)$. Here, trisomy 4 was observed together with additional structural chromosomal aberrations. Most likely the oncogene MLLT10 in 10p12.31 was activated by the strong promoter of $H N R N P H 1$ in 5q35.3. In addition, the translocation of $5 \mathrm{q} 31.1$ to $3 \mathrm{p} 23$ brought in close proximity the gene $I L 3$, which has been shown to have an oncogenic effect on hematopoietic cells (29), to 6 OMIM genes listed in Table I, which could also potentially lead to overexpression of IL3.

MLLT10 gene. Rearrangements have previously been identified in both child and adulthood acute leukemia (30). The $t(10 ; 11)$ is a recurrent reciprocal translocation present in two common variants: $\mathrm{t}(10 ; 11)(\mathrm{p} 12 ; \mathrm{q} 23)$ and $\mathrm{t}(10 ; 11)(\mathrm{p} 12 ; \mathrm{q} 21)$; the latter tending to be more frequent in T-ALL patients (31). In addition, the $\mathrm{t}(10 ; 11)(\mathrm{p} 12 ; \mathrm{q} 23)$ mainly found in childhood AML is rarely observed in B-ALL and T-ALL (32). The MLLT10 gene encodes a leucine zipper protein that functions as a transcription factor. MLLT10 gene rearrangements are associated with a poor outcome due to the poor response to therapy $(33,34)$.

HNRNPH1 gene. While unbalanced structural aberration of chromosome 5 are common in myelodysplastic syndrome or AML $(35,36)$, they are less common in ALL. Still Brandimarte et al (14) previously identified the HNRNPHI 
gene as a new MLLT10 fusion partner in pediatric T-ALL, as we observed in our case of T-precursor cell ALL.

IL3 gene. Located in $5 \mathrm{q} 31.1$, the IL3 gene is a multipotent hematopoietic growth factor produced by activated T cells (37). Its involvement in malignancies was previously reported in B-ALL cases due to a $\mathrm{t}(5 ; 14)(\mathrm{q} 31 ; \mathrm{q} 32)$. Overexpression of IL3 was associated with unfavorable outcome in such cases (38).

$3 p 23$ region. Six OMIM genes are located in the breakpoint region of chromosome 3 in subband p23. These include: STT3B (source of immunodominant MHC-associated), GPDIL (glycerol-3-phosphate dehydrogenase 1-like), GADL1, (glutamate decarboxylase-like 1), OSBPL10 (oxysterol-binding protein-like protein 10), CMTM7 (CKLF-like MARVEL transmembrane domain containing 7) and CMTM8 (CKLFlike MARVEL transmembrane domain containing 8). It is difficult to determine which one might have provided a strong promoter for IL3 gene expression.

In conclusion, the study in particular of ALL cases with unexpectedly adverse outcome in retrospect and in detail by high resolution molecular approaches is warranted. In the present case the combination of FISH-banding, FISH with locus-specific probes and aCGH revealed trisomy 4 but apart from that a balanced aberrant karyotype, explaining the severe course of the disease in this case with adverse outcome. Even if this complex karyotype would have been identified at the time of diagnosis most likely no additional therapy other than the applied protocol (ALL-BFM 95) would have been used. Yet, the recurrence may have been detected much earlier in the case of available cytogenetic markers. Thus, the most comprehensive molecular (cyto)genetic analyses should be offered to each individual ALL case. Even though aCGH would not have detected the balanced translocations, the detectable trisomy 4 would have hinted at the malignant clone missed by banding cytogenetics. In conclusion, the present case is the first one presenting with combined trisomy 4 with a four-way translocation activating IL3 together with MLLT1O.

\section{Acknowledgements}

The present study was supported in part by the DAAD and KAAD.

\section{References}

1. Han X and Bueso-Ramos CE: Precursor T-cell acute lymphoblastic leukemia/lymphoblastic lymphoma and acute biphenotypic leukemias. Am J Clin Pathol 127: 528-544, 2007.

2. Moorman AV, Richards SM, Martineau M, et al: Outcome heterogeneity in childhood high-hyperdiploid acute lymphoblastic leukemia. Blood 102: 2756-2762, 2003.

3. Chilton L, Buck G, Harrison CJ, et al: High hyperdiploidy among adolescents and adults with acute lymphoblastic leukaemia (ALL): cytogenetic features, clinical characteristics and outcome. Leukemia 28: 1511-1518, 2014.

4. Heerema NA, Sather HN, Sensel MG, et al: Prognostic impact of trisomies of chromosomes 10,17 , and 5 among children with acute lymphoblastic leukemia and high hyperdiploidy $(>50$ chromosomes). J Clin Oncol 18: 1876-1887, 2000.

5. Paulsson K, Forestier E, Andersen MK, et al: High modal number and triple trisomies are highly correlated favorable factors in childhood B-cell precursor high hyperdiploid acute lymphoblastic leukemia treated according to the NOPHO ALL 1992/2000 protocols. Haematologica 98: 1424-1432, 2013.
6. Gupta V and Chun K: Trisomy 4 as the sole cytogenetic abnormality in a patient with T-cell acute lymphoblastic leukemia. Cancer Genet Cytogenet 152: 158-162, 2004.

7. Paulsson K, Panagopoulos I, Knuutila S, et al: Formation of trisomies and their parental origin in hyperdiploid childhood acute lymphoblastic leukemia. Blood 102: 3010-3015, 2003.

8. Gruszka-Westwood AM, Horsley SW, Martinez-Ramirez A, et al: Comparative expressed sequence hybridization studies of high-hyperdiploid childhood acute lymphoblastic leukemia. Genes Chromosomes Cancer 41: 191-202, 2004.

9. Kebriaei P, Anastasi J and Larson RA: Acute lymphoblastic leukaemia: diagnosis and classification. Best Pract Res Clin Haematol 15: 597-621, 2002.

10. Cauwelier B, Dastugue N, Cools J, et al: Molecular cytogenetic study of 126 unselected T-ALL cases reveals high incidence of TCRbeta locus rearrangements and putative new T-cell oncogenes. Leukemia 20: 1238-1244, 2006.

11. Inaba H, Greaves M and Mullighan CG: Acute lymphoblastic leukaemia. Lancet 381: 1943-1955, 2013.

12. Berger R, Dastugue N, Busson M, et al: $\mathrm{t}(5 ; 14) / \mathrm{HOX} 11 \mathrm{~L} 2-$ positive T-cell acute lymphoblastic leukemia. A collaborative study of the Groupe Français de Cytogénétique Hématologique (GFCH). Leukemia 17: 1851-1857, 2003.

13. Borel C, Dastugue N,Cances-Lauwers V, et al:PICALM-MLLT10 acute myeloid leukemia: a French cohort of 18 patients. Leuk Res 36: 1365-1369, 2012.

14. Brandimarte L, Pierini V, Di Giacomo D, et al: New MLLT10 gene recombinations in pediatric T-acute lymphoblastic leukemia. Blood 121: 5064-5067, 2013.

15. Coustan-Smith E, Mullighan CG, Onciu M, et al: Early T-cell precursor leukaemia: a subtype of very high-risk acute lymphoblastic leukaemia. Lancet Oncol 10: 147-156, 2009.

16. Inukai $\mathrm{T}$, Kiyokawa $\mathrm{N}$, Campana $\mathrm{D}$, et al: Clinical significance of early T-cell precursor acute lymphoblastic leukaemia: results of the Tokyo Children's Cancer Study Group Study L99-15. Br J Haematol 156: 358-365, 2012.

17. Zhang J, Ding L, Holmfeldt L, et al: The genetic basis of early T-cell precursor acute lymphoblastic leukaemia. Nature 481: $157-163,2012$.

18. Claussen U, Michel S, Mühlig P, et al: Demystifying chromosome preparation and the implications for the concept of chromosome condensation during mitosis. Cytogenet Genome Res 98: 136-146, 2002.

19. Liehr T and Claussen U: Current developments in human molecular cytogenetic techniques. Curr Mol Med 2: 283-297, 2002.

20. Liehr T, Heller A, Starke H, et al: Microdissection based high resolution multicolor banding for all 24 human chromosomes. Int J Mol Med 9: 335-339, 2002.

21. Weise A, Heller A, Starke H, et al: Multitude multicolor chromosome banding (mMCB) - a comprehensive one-step multicolor FISH banding method. Cytogenet Genome Res 103: 34-39, 2003.

22. Weise A, Mrasek K, Fickelscher I, et al: Molecular definition of high-resolution multicolor banding probes: first within the human DNA sequence anchored FISH banding probe set. J Histochem Cytochem 56: 487-493, 2008.

23. Bernard OA, Romana SP, Poirel H and Berger R: Molecular cytogenetics of $\mathrm{t}(12 ; 21)$ (p13;q22). Leuk Lymphoma 23: 459-465, 1996.

24. Usvasalo A, Räty R, Harila-Saari A, et al: Acute lymphoblastic leukemias with normal karyotypes are not without genomic aberrations. Cancer Genet Cytogenet 192: 10-17, 2009.

25. Mkrtchyan H, Glaser M, Gross M, et al: Multicolor-FISH applied to resolve complex chromosomal changes in a case of T-ALL (FAB L2). Cytogenet Genome Res 114: 270-273, 2006.

26. Bains A, Lu G, Yao H, et al: Molecular and clinicopathologic characterization of AML with isolated trisomy 4. Am J Clin Pathol 137: 387-394, 2012.

27. Moreau $\mathrm{P}$, Talmant $\mathrm{P}$, Milpied N, et al: Trisomy 4 associated with acute lymphocytic leukaemia. Br J Haematol 78: 576, 1991.

28. Yip SF, Wan TS, Chan LC and Chan GC: Trisomy 4 as sole karyotypic abnormality in acute lymphoblastic leukemia: different clinical features and treatment response between $\mathrm{B}$ and T phenotypes? Cancer Genet Cytogenet 164: 94-95, 2006.

29. Steelman LS, Algate PA, Blalock WL, et al: Oncogenic effects of overexpression of the interleukin-3 receptor on hematopoietic cells. Leukemia 10: 528-542, 1996. 
30. DiMartino JF, Ayton PM, Chen EH, et al: The AF10 leucine zipper is required for leukemic transformation of myeloid progenitors by MLL-AF10. Blood 99: 3780-3785, 2002.

31. Asnafi V, Radford-Weiss I, Dastugue N, et al: CALM-AF10 is a common fusion transcript in T-ALL and is specific to the TCRgammadelta lineage. Blood 102: 1000-1006, 2003.

32. Coenen EA, Raimondi SC, Harbott J, et al: Prognostic significance of additional cytogenetic aberrations in 733 de novo pediatric 11q23/MLL-rearranged AML patients: results of an international study. Blood 117: 7102-7111, 2011.

33. Dreyling MH, Schrader K, Fonatsch C, et al: MLL and CALM are fused to AF10 in morphologically distinct subsets of acute leukemia with translocation $\mathrm{t}(10 ; 11)$ : both rearrangements are associated with a poor prognosis. Blood 91: 4662-4667, 1998.

34. Caudell D and Aplan PD: The role of CALM-AF10 gene fusion in acute leukemia. Leukemia 22: 678-685, 2008.
35. Crescenzi B, La Starza R, Romoli S, et al: Submicroscopic deletions in 5q-associated malignancies. Haematologica 89: 281-285, 2004

36. Kayser S, Zucknick M, Döhner K, et al: Monosomal karyotype in adult acute myeloid leukemia: prognostic impact and outcome after different treatment strategies. Blood 119: 551-558, 2012.

37. Mangi MH and Newland AC: Interleukin-3 in hematology and oncology: current state of knowledge and future directions. Cytokines Cell Mol Ther 5: 87-95, 1999.

38. Gallego M, Coccé M, Felice M, et al: A new case of $\mathrm{t}(5 ; 14)$ (q31;q32) in a pediatric acute lymphoblastic leukemia presenting with hypereosinophilia. Atlas Genet Cytogenet Oncol Haematol 16: $183-184,2012$ 